\title{
Prevalence of Viral, bacterial, management and parasitic poultry diseases from 2002 -2004 in Duhok
}

\author{
Luqman Taib omer /Duhok \\ University /college of veterinary Medicine
}

\begin{abstract}
:
The visit, connection and postmortem investigations of poultry diseases were conducted in different farms of Duhok a total of 750 either dead or sick birds were examined. The incidence of OMPHALITIS ( 30\% in 2002 ,35\% in 2003 and the 50\% ) followed 20\%, 30\%, and 32\% in the 2002, 2003, and 2004 respectively . and the other cases were little in number in both year in all farms like the Newcastle disease and IBD also like the parasitic diseases.
\end{abstract}

\section{Introduction}

The poultry production after the first Gulf wore, in Iraq was seas and the background of more poultry project were destroyed. And at that time the poultry production characterized by the small scale operation, almost all all-rural household has some poultry and women are the raisers of theses chickens. After implementation of the SCR 986 the veterinary instruction has revived. The FAO can gives some primary material which are necessary for poultry feed like concentrated proteins and soya bean mail, with some other material that had has some effect on these project. After that some or most of project can help him self and start in production. 


\section{Material and methods:-}

A total number of 750 dead or sick birds of different age were received from all over the GOVERNORANT at the special veterinary clinic and the central laboratory in the directory of animal wealf and veterinary in Duhok from the year January, 2002 to December 2004. In most of the cases a diagnosis was made on the basis of the history, clinical signs and PM.

\section{Results:}

During the last three year, a total of 750 dead or sick birds were examined where 250 in the year 2002, 250 in the year 2003 and 250 in the year 2004. Highest incidence was observed in cases OMPHALITIS ( $30 \%$ in $2002,35 \%$ in 2003 and the $50 \%$ is the rate of infection in year2004. The most important cause poor incubator and hatchery sanitation, excessive incubator humidity, and chilling or overheating of newly hatched poultry. Navel closure is incomplete, permitting ( if present) entry of variety of intestinal bacterial. Poor hatching-egg shell quality permits bacterial penetration, thus increased omphalitis. Incubation is 8-24 hours and disease course is 6 to 7 days. And the clinical signs chicks are weak and unthrifty, with enlarged abdomens, moist inflamed navels, pasted vents, and lack of body tone. Hatchings huddle, and severely infected birds die within the first week. Expected mortality is 1 to 3 percent. Incidence and losses vary from hatch to hatch depending on incubator hygiene, and from breeder flock to breeder flock according to shell quality of the hatching eggs. Mortality equals morbidity with this disease. ( 1 )

Chronic respiratory disease was the second about $20 \%, 30 \%$, and $32 \%$ in the 2002, 2003, and 2004 respectively. It is a contagious disease of 
poultry of all ages, characterized by Air Sacculitis with yellow caseous (cheesy) exudates. Caused by Mycoplasma gallisepticum (( $\left.\begin{array}{ll}1\end{array}\right)$.

E.coli often infects respiratory tract of birds concurrently infected with various combinations varies viruses and mycoplasmas. Apparently, the damaged respiratory tract becomes extremely susceptible to invasion by E.coli ( 5 ). The resulting disease is commonly called air sac disease or chronic respiratory disease (CRD) ( 5 )

The most characteristic signs of the naturally occurring disease in adult flocks are tracheal rales, nasal discharge, and coughing. Feed consumptions are reduced and birds lose weight. In laying flocks, egg production declines but is usually maintained at a lowered level. (2)

Case of keratoconjunctivitis apparently caused by MG were reported in commercial layer chickens in Japan ( 124 ). Chickens showed swelling of the facial skin and the eyelids, increased lacrimation, congestion of conjunctival vessels and respiratory rales. ( 142 )

And the most case of CRD was occurs after hard vaccination which is also the predisposing factor of CRD. (6)

And the cases aflatoxicosis in the area were occurs specially during use of bad material in feed formula or use bad stored material especially Soya bean mail and 20 cases of aflatoxicosis recorded in 2002,21 in 2003 and 30 in 2004.

However the nutritional deficiency also occurs and the most important time when the wheat was stored for long times, when there was imbalance in the nutrition formula and the broken wheat when used in feed .And expire oil or the formula stored for long time specially at summer season. And most case were vitamin B1,E deficiency with Vitamin E deficiency as a 3 case in 2003 and Vitamin B1 deficiency 2 in 2002 and 3 in 2004. The vitamin B1 deficiency characterized by onset is sudden in young chicks but more gradual in mature birds. Anorexia is 
followed by loss of weight, ruffled feather, leg weakness, and an unsteady gait. Adult chickens often show a blue comb. The chicken characteristically sits on its flexed legs and draws back the head in a "stargrazing " position. Retraction of the head is due to paralysis of the anterior muscles of the neck. (6)

The two important disease which were more distributed in all world also we have the problem with them and with hard vaccination programme we can seized the out break of them (IBD and ND), and few case have been recorded 2, 3 case in 2002, 3, 1 cases in 2003 and 3, 2 case in 2004 for ND and IBD respectively, all these cases which were occurs was during fall of vaccine or the aflatoxine cases. (6)

Finally the parasitic diseases were found very few in numbers except coccidisis (6 cases) $2.4 \%$, ( 7 cases) $3 \%$ and (4 cases) $1.6 \%$ in the 2002 , 2003 and 2004 respectively occurs in Duhok during these three years. Specially in winter season except two case occurs in summer in broiler parent .And Ascarida galli in parent bred have been recorded in three year in parent stock especially at age 15-20 months, and also in neglected case. 2002, (5 cases), in 2003 (12cases) and 20 cases in 2004

Only one case of avian pox recorded in parent stock at age 12 months. Two case of dermatitis have been recorded one in 2002 and other in 2004 which was helps the cannibalism. Also some other cases which were need more important diagnostic methods like ELISA and other new diagnostic methods. 


\section{References}

L.Dwight Schwartz, D.V.M. (1994). Poultry health Handbook.

University of Pynnsylvania $4^{\text {th }}$ edition. PP 61 and 137

2- $\quad$ Mohammed, H.O., T.E.Crpenter, and Y. Yamamoto. 1987.

Economic impact of Mycoplasma gallisepticum and M. synoviae in commercial layer flocks. Avian Dis. 31;477-482

3- Nunoya, T., T.Yagihashi,M. Tajima and Y.Nagasawa.1995.

Occurrence of keratoconjuctivitis apparently caused by

Mycoplasma gallisepticum in layer chickens. Vet. Pathol 32; 11-

18.

4- Soeripto, K.G. Whithear, G.S. Cottwe , and K.E. Harigan.1989.

Virulence and transmissibility of Mycoplasma gallisepticum.Aust. Vet J 66:65-72

5- Gross,W.B.1961. THE DEVELOPMENT OF AIR SAC DISEASE. Avian Dis.5; 431-439.

6- B.W.Calnek. H.John B., C.W.Beard., L.R.Mcdougald., Y.M. Salf . (1997).Diseases of poultry $10^{\text {th }}$ edition . pp 56, 134, 197. 